\title{
Crisis Management: Responding Effectively to Traumatic Crises
}

\section{James L. Greenstone}

DABECI, Fort Worth, Texas, USA

Crisis is in the eye of the beholder. Crisis involves stress; unusual stress that renders the sufferer unable to cope with their life as they usually would. A disaster exists when the resources available to address the emergency are less than those needed to address the needs of the victims and the overall situation. A disaster can be of any size. The issue is whether or not the needs of those affected by the disaster can be met with the resources available at that time. Overwhelmed resources usually equals disaster as differentiated from an emergency in which adequate resources can be utilized to resolve or to manage the needs of those affected. Here, we are about crisis and about the possibility of overwhelmed resources both personal and public. The greater and more personal the perceived threat, the greater the likelihood for crisis to occur (Figure 1).

\section{Publication History:}

Received: February 21, 2019

Accepted: March 04, 2019

Published: March 06, 2019

\section{Keywords:}

Crisis management, Disaster, Psychological structuring, Crisis intervention, Stimulus situation

can be a determiner of a person's susceptibility to experiencing crisis in their life at a particular time. No one is immune to crisis. Enough stress at the wrong time and in the particular person at that time can

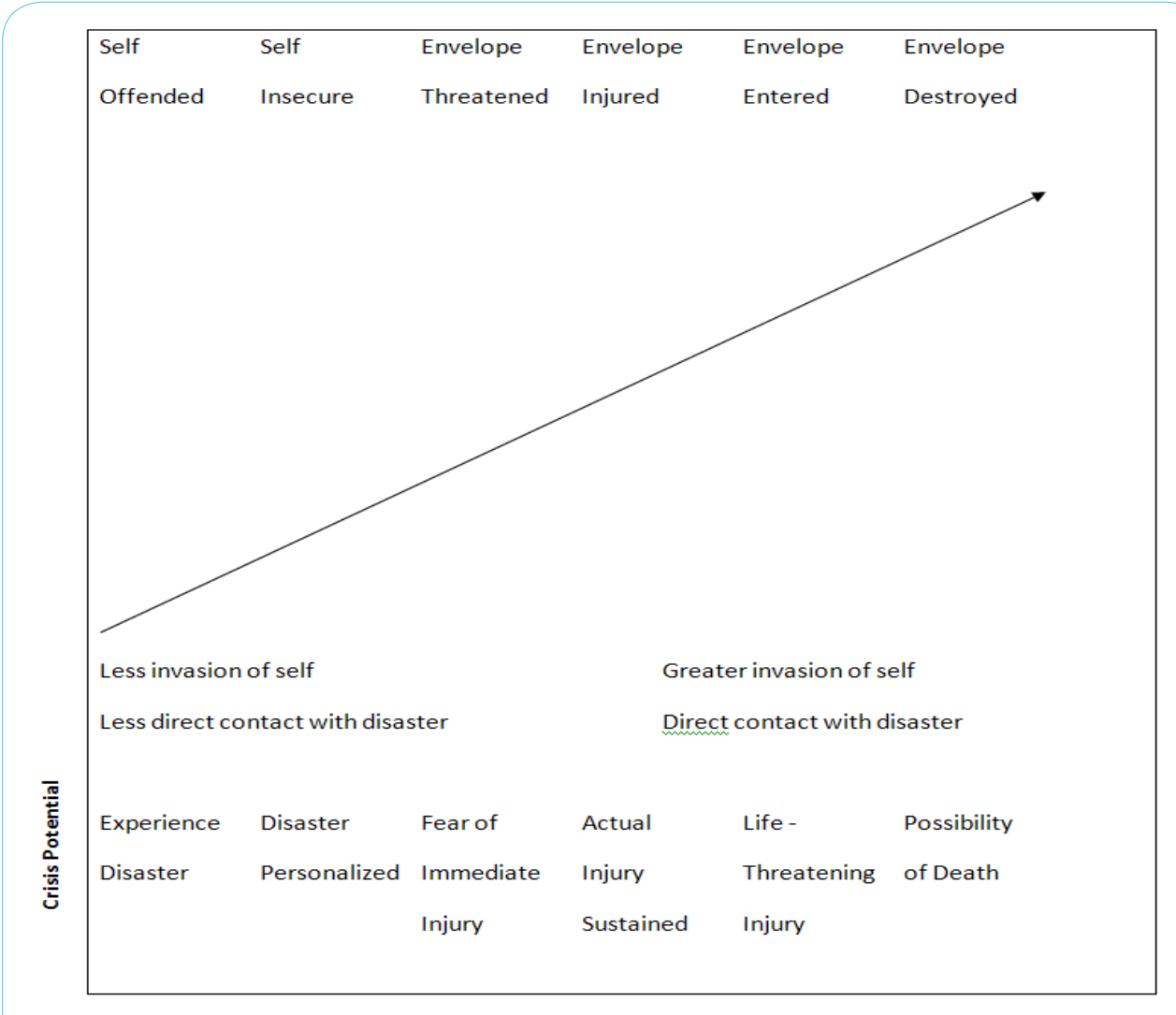

Increased direct contact with the disaster and the likelihood of personal crisis

Figure 1: The Disaster - Crisis Continuum.

NB: This may be experienced by the victim or by significant others of the victim.

Adapted from and based on the crime-crisis continuum developed by Dr. J.L. Greenstone.(C1982 and 2008.

The crisis trilogy presents a way of understanding the causation in crisis situations. The trilogy involves events occurring that are (1) sudden in onset, (2) unexpected by the victim or their significant others, and (3) appear to be arbitrary in nature. All three are major sources of unusual stress. Because crisis is in the eye of the beholder, what is unusual stress for one may not be for someone else. Take a look at the Crisis Cube, (Figure 2) to help in understanding this concept. Level of functioning overall, presence or absence of functional emotional problems, experience handling stress and similar daily-life behaviors
"Corresponding Author: Dr. James L. Greenstone, DABECI, Fort Worth, Texas, United State of America; E-mail: dr.james.greenstone@gmail.com

Citation: Greenstone JL (2019) Crisis Management: Responding Effectively to Traumatic Crises. Int J Psychol Behav Anal 5: 159. doi: https://doi. org/10.15344/2455-3867/2019/159

Copyright: (c) 2019 Greenstone. This is an open-access article distributed under the terms of the Creative Commons Attribution License, which permits unrestricted use, distribution, and reproduction in any medium, provided the original author and source are credited. 
Citation: Greenstone JL (2019) Crisis Management: Responding Effectively to Traumatic Crises. Int J Psychol Behav Anal 5: 159. doi: https://doi.org/10.15344/2455$3867 / 2019 / 159$

Page of 6

mean crisis even for the strongest of us. This includes responders and crisis interveners as well. Sherif's [1] principles described below are very helpful in understanding this and in preparing for such eventualities (Figure 3 and Figure 4).
Sherif and Sherif [1] provided their basic and unyielding principles of social interaction that provide a background for our understanding of crises and Emotional First Aid. The following are adaptations of these remarkable principles that Sherif believed apply in all social

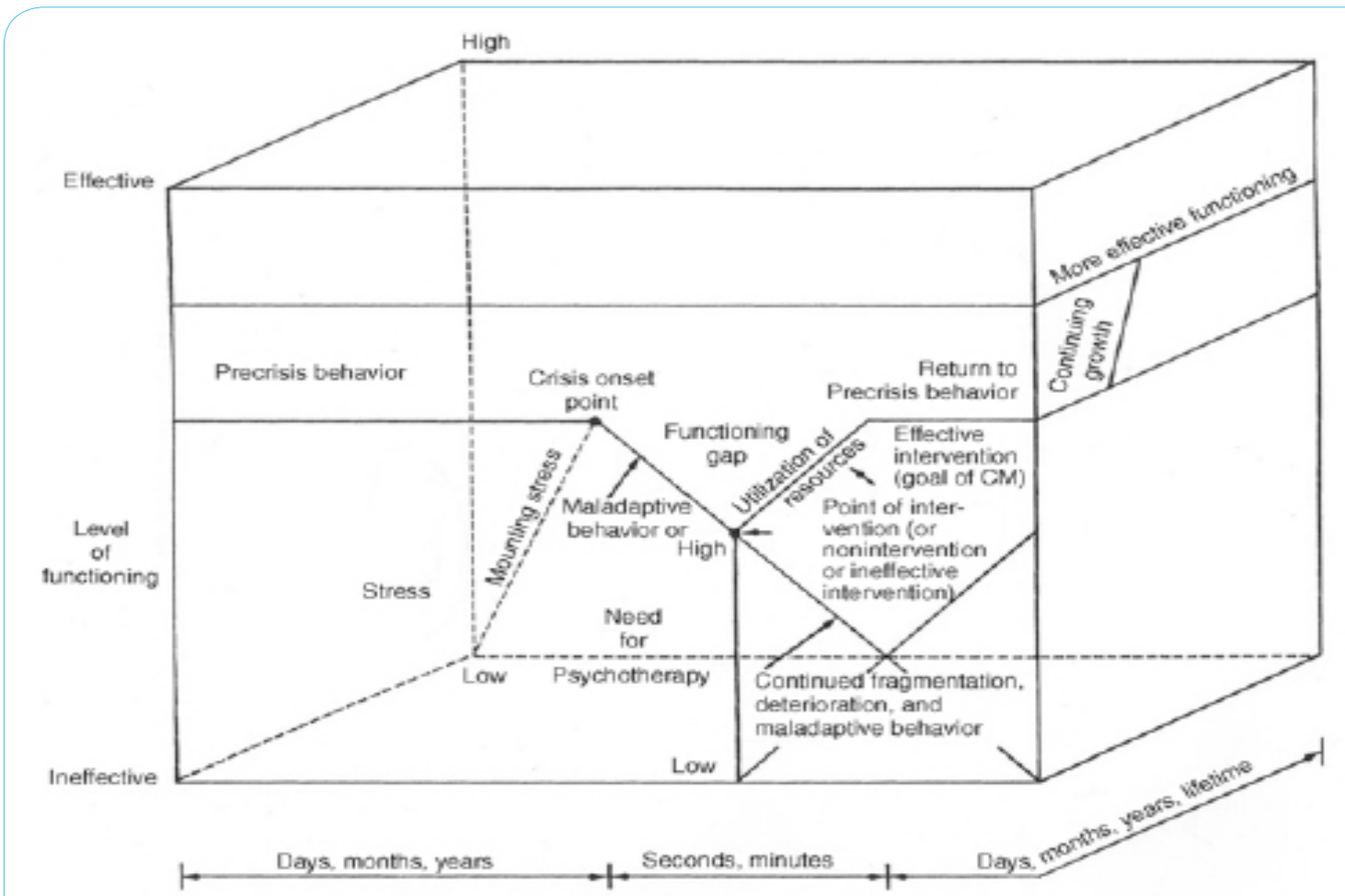

Figure 2: The Crisis Cube (2010).

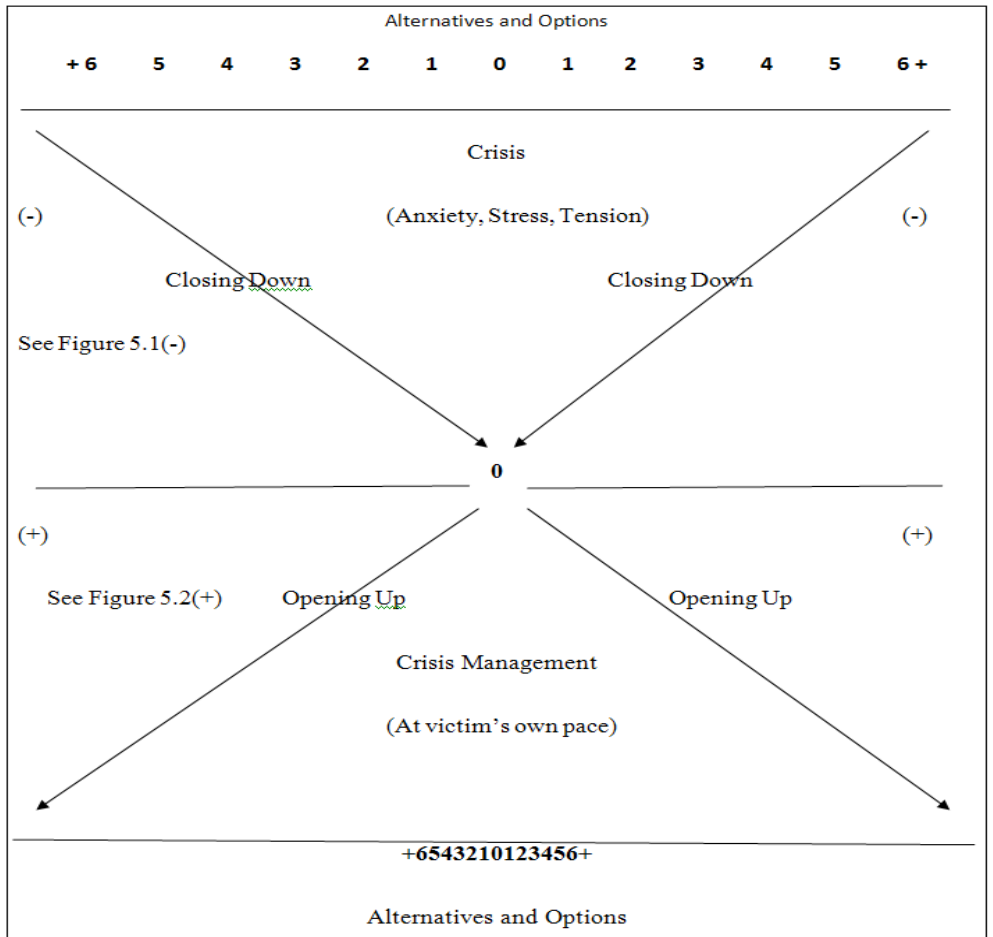

Figure 3: Crisis Management. How crises tend to emotionally shut down sufferers and how effective crisis management and emotional first aid can reverse the process. (Adapted from Evarts, Greenstone, Et Al, 1983). 
Citation: Greenstone JL (2019) Crisis Management: Responding Effectively to Traumatic Crises. Int J Psychol Behav Anal 5: 159. doi: https://doi.org/10.15344/2455$3867 / 2019 / 159$

situations. The implications for understanding and for responding effectively to those in crisis can be easily seen. What we do is based on what we know about what the sufferer or victim is doing, thinking or experiencing.

1. Experience and behavior constitute a unity.

2. Behavior follows central psychological structuring. See figure above.

3. Psychological structuring is jointly determined by external and internal factors. See figure above.

4. Internal factors such as motives, attitudes, etc. and experience are inferred from behavior.

5. The psychological tendency is toward structuring of experience.
6. Structured stimulus situations set limits to alternatives in psychological structuring.

7. In unstructured stimulus situations, alternatives in psychological structuring are increased.

8. The more unstructured the stimulus situation, the greater the relative contribution of internal factors in the frame of reference.

9. The more unstructured the stimulus situation, the greater the relative contribution of external social factors in the frame of reference.

10. Various factors in the frame of reference have differing relative weights.

11. Psychological activity is selective.

12. Human psychological functioning is typically on the conceptual level [1].

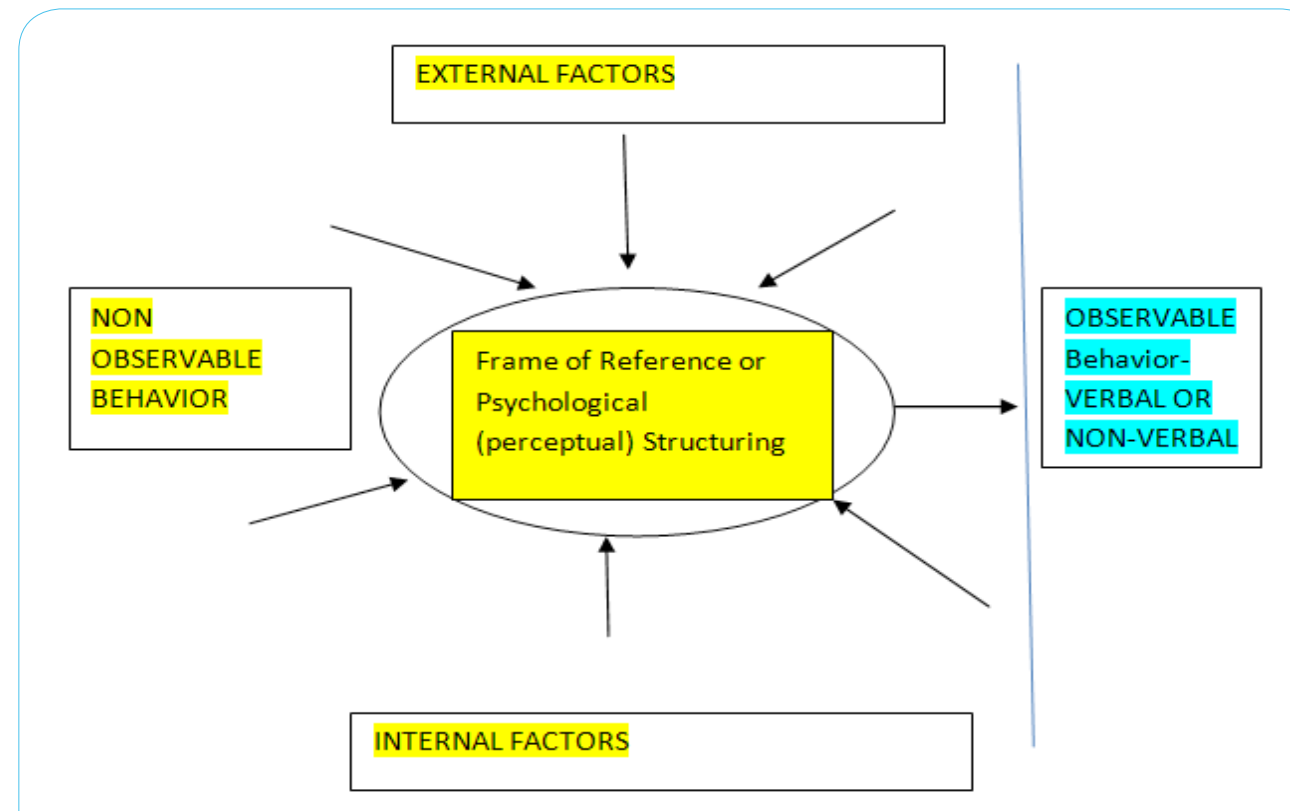

Figure 4: Psychological Structuring.

External Factors in the external stimulus situation

\begin{tabular}{l|} 
Objects \\
Cultural products \\
Person \\
Groups
\end{tabular}

Internal Factors

Motives
Attitudes
Emotions
Various states of the organism
Effects of past experiences

Figure 4.1: Internal and External Factor. 
Within the crisis trilogy, suddenness refers to the way in which a person may encounter the stressful event or events leading to the possibility of crisis. For example, someone jumps out from behind a tree and attacks a passer-by. No delay, no warning, just the sudden attack. The passer-by may have walked this way many times without incident and has little expectation of problems. The problem occurs as described and was not expected; the second aspect of the trilogy. The third aspect of the trilogy asks, "Why me." Of all the people to whom this could have happened, why did it happen to me? The concerns expressed can be a great source of added stress to the victim of this attack. Taken together or even separately, these factors can be a source of unusual stress capable of overwhelming the usual coping skills of the sufferer. When this trilogy is applied to the occurrence of a disaster, the crisis reactions become a little more predictable and understandable. And, in the same way, some victims will react and respond differently than others based on the more or less personal resources available to them. For instance, someone who has gone through a crisis or a disaster previously, and has resolved or at least managed the issues that were involved in an effective manner, may be better able to cope in the instant situation. Those who have used the "band-aid" approach to crisis management or to life's problems in general, may have unresolved issues that will make the current experience much more difficult to handle. Those who effectively and successfully deal with high stress issues and personal problems when they occur, rather than denying or refusing to deal with them, often come through their present crisis in much better shape emotionally than the second group. The need for additional and or ongoing counseling or psychotherapy after the fact may be minimized as well.

Tendency to close down emotionally.
Access to resources decrease.
Supports harder to access or unavailable.
Problems solving ability decreases.
Paladaptive behavior increases
Possibility of physical violence escalates.
Prigher levels of frustration.
Opterisis behavior inaccessible.
Difficulty seeing helpful possibilities.

Figure 5.1: (-) What happens during crisis (-).
The effectiveness of the crisis intervention may be another important factor in this equation. The better we do now, the less we will probably have to do later (Figure 5 and Figure 6).

Another crucial aspect of a crisis is that a crisis will not go on forever. The human body and mind cannot handle crisis-level stress indefinitely. Crises are self-limiting. If an intervener did nothing to assist the sufferer, the crisis will still end on its own. The issue then becomes the condition of the victim when the crisis has ended. The ultimate self-resolution, without intervention, could be death due to the body's need or the sufferer's need to end the pain caused by the excessively heightened stress. Immediate and effective intervention, that seeks to stop the downward spiral of maladaptive behavior, will usually yield better results. An intervener who knows what to do and when and how much can prevent the predictable outcomes to unresolved heightened stress and perhaps even reduce the need for professional psychological assistance later. Figure 2 helps to explain this relationship.

No one doubts the importance of crisis intervention. What may be in doubt at times is how well prepared the intervener is to deal with the vital issues at hand and to understand their origins. Crisis Intervention seeks to do only what is absolutely necessary for the victim and nothing more. Not too much, not too little, but just the right amount. To do this, interveners must take the time to train in a practical way and to learn the underpinnings of crisis intervention. Just wanting to help is not enough. Having just the skills without

Tendency to open up at sufferer's own pace.
Maladaptive behavior decreases.
Resource utilization increases.
Problem solving skills increase.
Access to or recognition of support systems increase.
Possibilities for growth increase.
Chances of physical violence decrease.
Dikelihood of returning to pre-crisis behavior increases.
Ability to get on with one's life increases.
Opens interactions with others.

Figure 5.2: (+) What happens during crisis management or crisis intervention $(+)$ 
the understanding may cause more harm than good. Jumping into something with inappropriate techniques for the situation or thinking that one size fits all, may be a major mistake with overwhelming consequences. And, as you may have read elsewhere, knowing what to stay out of is just as important as knowing what to get involved in when doing crisis intervention regardless of the circumstances. Such reasoning comes from both training and education in this discipline.

The pre crisis functioning, either effective or less effective, of an individual has probably existed over a long period of time prior to the instant situation. The way previous crises have been handled, presence or absence of functional mental disorders, level of general daily function, adequacy of coping and survival skills, are all part of this pre crisis picture.

At the other end of the continuum, (Figure 2) are the potential life changing or life altering consequences of experiencing a crisis in one's life. These too can go on for significant periods of time long after the crisis has ended. In fact, it may be possible to achieve even greater levels of functioning in one's life depending on how the current crisis was handled. How it was handled may well depend on the effectiveness of the intervener. If the intervener proves not only effective but also trustworthy, the sufferer may be willing to accept suggestions for additional assistance as needed to develop higher level life skills.

Crisis intervention is about management and not about resolution. Therapy may be a source of resolution of problems. Crisis intervention is about trying to find a way to manage what is being experienced so that the crisis' destructive influences are diminished. It is important to note that the goal of crisis intervention is extremely limited and short term. As mentioned above, higher levels of functioning are possible. However, the goal of the crisis intervener when assisting a sufferer in crisis is to return that sufferer to their own level of pre crisis functioning. No more, no less. If the intervener accomplishes this, the goals of crisis intervention have been met. What may happen subsequently is lagniappe. While pre and post crisis functioning timeline may be measured in days or weeks or years, the time needed for effective crisis intervention is measured in seconds and maybe minutes only. Any additional time you may get is lagniappe for you as the intervener as well. See Figure 2. Crisis interveners have been compared to emergency room medical personnel in that their effective reactions, timing, and utilization of resources must be immediate and sure; so, similarly for the intervener. If a counselor makes an error in a regular weekly session, they may be able to correct the error by phone or in person at the next session. On the other hand, the crisis intervener, like their emergency room counterparts, may have only one bite at the apple as it were. They may have one quick opportunity to be effective and failing that no other opportunity to try again. What the intervener does must be correct the first time without dependence on the possibility of a do-over. This may be why not all who want to be can actually be crisis interveners; just as some may not be able to work in an emergency room although comfortable and competent in other professional settings.

\section{A Final Note}

Crises are often unexpected, sudden, and arbitrary. They are time sensitive and time specific. All crises end regardless of what an intervener may or may not do. The real question is where will the crisis end if the intervener does nothing or is ineffective. Remember that stress in unusual proportions for that person is key to understanding crisis. Interveners must react and be effective within seconds or minutes to avert additional problems. While the goal of crisis management, not resolution, is to return the sufferer

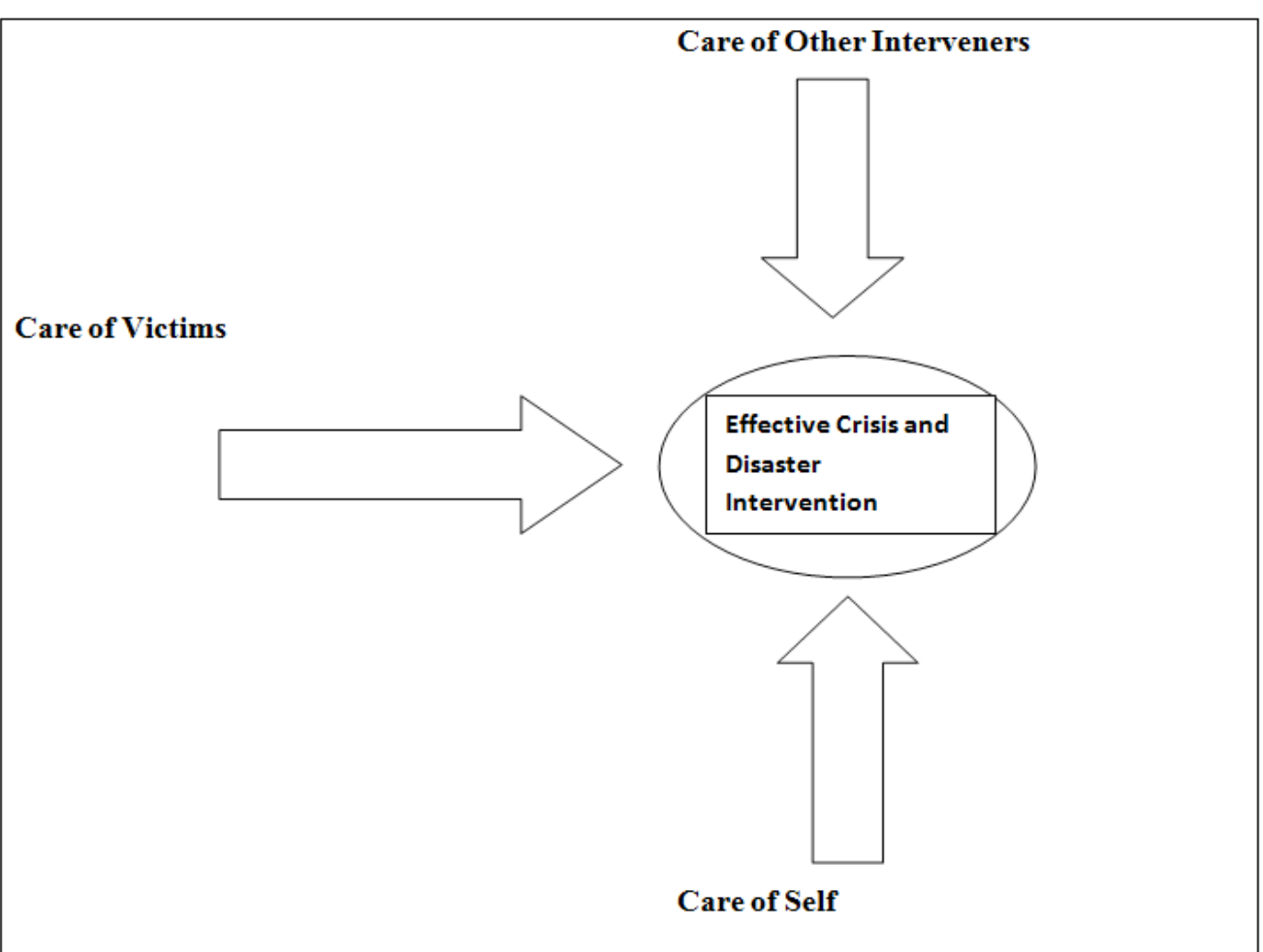

Figure 6: To remain helpful, we must remain effective. 
to their level of pre crisis functioning, greater gains for that sufferer may be possible depending on the credibility of the intervener and the effectiveness of the intervention. Crisis intervention or Emotional First Aid is comparable to physical first aid and must be administered with the same skill and alacrity. Never forget that knowing what to stay out of is just as important to the intervener as knowing in what to become involved.

\section{Competing Interests}

The author declare no competing interests.

\section{References}

1. Advanced disaster life support (2006) National Disaster Life Support Foundation. Chicago: American Medical Association.

2. Agency for Healthcare Research and Quality (2005) Altered standards of care in mass casualty events. Washington, DC: U.S. Department of Health and Human Services.

3. Beevers CG, Lee HJ, Wells TT, Ellis AJ, Telch MJ, et al. (2011) Association of predeployment gaze bias for emotional stimuli with later symptoms of PTSD and depression in soldiers deployed in Iraq. Am J Psychiatry 168: 735 741.

4. Centers for Disease Control, National Institute for Occupational Safety and Health (2002) Emergency response workers: Traumatic stress incidence. Atlanta, Georgia.

5. Certification commission for healthcare interpreters.

6. Clorox bleach for emergency water purification.

7. Disaster Mental Health Services, Substance Abuse and Mental Health Services Administration (2002) Self-care tips for emergency and disaster response workers, SAMHSA. Washington DC.

8. DiVasto PV (1996) Negotiating with foreign language-speaking subjects The FBI Law Enforcement Bulletin 65: 6-10.

9. Evarts WR, Greenstone JL, Kirkpatrick GJ, Leviton SC (1983) Winning through accommodation: The mediator's handbook. Dubuque, Iowa: Kendall/Hunt Publishing Company.

10. Greenstone JL (2011) Tactical combat casualty care training for state defense forces medical units. Journal of the State Defense Forces Publication Center 6: $20-25$

11. Greenstone JL (2010) Use of interpreters with crisis intervention teams, behavioral health units and medical strike teams: Responding appropriately and effectively. Int J Emerg Ment Health 12: 79-82.

12. Greenstone JL (2008) The elements of disaster psychology: Managing psychosocial trauma - an integrated approach to force protection and acute care. Springfield, Illinois.

13. Greenstone JL (1993) Critical incident stress debriefing and crisis management. Austin, TX: Texas Department of Health, Bureau of Emergency Management.

14. Greenstone JL, Leviton SC (1982) Crisis intervention: Handbook for interveners. Dubuque, Iowa: Kendall/Hunt Publishing Company.

15. Greenstone JL, Leviton SC (2010) Elements of crisis intervention: Crises and how to respond to them. Pacific Grove, CA: Brooks/Cole Publishing Company.

16. Greenstone JL, Sharon L (1981) Hotline: Crisis intervention directory. New York: Facts on File.

17. Greenstone JL (2005) The elements of police hostage and crisis negotiations: Critical incidents and how to respond to them. Binghamton, New York: The Haworth Press, Inc.

18. Groopman J (2007) How doctors think. New York: Houghton-Mifflin.

19. Holdeman E (2008) Disaster denial. Cowlitz County: Department of Emergency Management.

20. Personal equipment check list (2010) Disaster Medical Assistance Team TX-4.Retrieved.

21. Reese SM (2010) Exclusive ethics survey: Should I keep this patient alive? Medscape Medical Ethics.
22. Ripley A (2006) Floods, tornadoes, hurricanes, wildfires, earthquakes: Why we don't prepare. Time Magazine 168: 10-16.

23. Rosenbluh ES (1981) Emotional first aid: Crises - their development and systems of intervention. Louisville, KY: American Academy of Crisis Interveners.

24. Rosenbluh ED (1986) Crisis counseling: Emotional first aid. Dubuque, Iowa: Kendall/Hunt Publishing Company.

25. Schwartz R, McManus J, Swienton RE (2007) Tactical and operational emergency medical services command and support. Philadelphia.

26. Sherif, Sherif, C. (1948) An outline of social psychology. New York: Harper and Row Publishers.

27. The psychology of risk perception (2011) Harvard Mental Health Letter 27: 6.

28. Unconventional medic (2010). American Rescue Products, Incorporated.

29. http://en.wikipedia.org/wiki/Field_guideWikipedia,\%20http:/en.wikipedia. org/wiki/Field_guide.

30. Yun K, Lurie N, Hyde PS (2010). Moving mental health into the disasterpreparedness spotlight. New England Journal of Medicine 363 : 1193-1195. 